\title{
Aging, Technology, and Psychology
}

\section{Models of Assistive Device Use Viewed From an Action-Theoretical Perspective on Lifespan Development}

\author{
Diana Abriø and Thomas Boll
}

\author{
Department of Behavioural and Cognitive Sciences, Institute for Lifespan Development, Family, and Culture, \\ University of Luxembourg, Luxembourg
}

\begin{abstract}
Many older people suffer from functional declines and activity limitations, which reduce their autonomy and quality of life. Assistive technologies (ATs) could dampen such effects. However, many older people do not use ATs and it is important to understand, why they give away their benefits. In this article, we look at older peoples' use of ATs from an action perspective on human development elaborated by Brandtstädter and colleagues. We review from this viewpoint models of AT use created mostly in information systems technology, business administration, and management sciences. The major focus is on the extent to which these models consider the relevant internal (mental) and external context of AT use, possible action alternatives, and autonomous, vicarious, and joint modes of decision-making about AT use. Systematic literature searches in PsycINFO, MEDLINE, and Google Scholar led us to 23 models. None of them contained as central variables any perceived discrepancies between the actual and desired developmental situation or any goals to reduce these discrepancies. No model included action alternatives to AT use beyond non-use such as trying harder on oneself, making environmental adaptations or using personal support. All models conceive of AT use as an act of the individual user, but neglected decision making about AT use by other persons on his or her behalf or a joint decision making of a potential user together with other persons (e.g., relatives). We discuss the background of these gaps, possibilities of a more comprehensive modeling of AT use, and practical implications (e.g., developmental counseling).
\end{abstract}

Keywords: assistive technologies, use, models, review, action perspectives on development in old age

A gradual decline in functional capacity and a growing risk of care dependency constitute major concerns of older people (e.g., World Health Organization, 2015). One way of coping with these problems is the use of assistive technologies (ATs). As we are primarily concerned with ATs for older people (many of whom have functional limitations), we regard it as particularly useful to consider any tool or technical system as ATs that enables the performance of the activities mentioned in the International classification of Functioning, Disability and Health (ICF) by the World Health Organization (2001). The ICF offers psychologists the advantage of a structured overview of the wide range of human activities that may be impaired - and that ATs can help to carry out. Another advantage is that the meticulous definitions of the various activities make explicit the central components of each activity that may need to be specifically supported by ATs (Abrilahij \& Boll, 2018), namely the bio-mechanical and/or instrumental-actional, and/ or norm fulfillment components (e.g., drinking in a culturally appropriate manner).
To exploit the benefits of ATs for helping older people to age in place, understanding facilitation and inhibition of the use of ATs in old age is essential (Abrilahij \& Boll, 2019). Facilitating the use of ATs requires knowledge of factors that can serve this function. Several empirical studies shed some light on them, but most of these studies are not based on explicit theoretical models. Doing so would have several advantages. Such models ideally integrate already existing knowledge about factors influencing AT use, allow researchers to derive new hypothesis about them, and can help practitioners to generate ideas about which factors to change by interventions for optimizing the use of ATs.

Two recent reviews covered various groups of AT use models mostly stemming from information systems technology, business administration, and management sciences (Alkhwaldi \& Kamala, 2017; Lai, 2017). Taken together, these articles provide helpful descriptions of the main components, strengths, and several problems of the models as well as their explanatory and predictive power. Yet, these reviews have severe limitations. First, some important 
models were not covered such as the Almere Model (Heerink, Kröse, Evers, \& Wielinga, 2010), the model of technology uptake by Schulz (2013) or the social cognitive model by Roelands, Van Oost, Depoorter, and Buysse (2002). Second, they have addressed only models of the use of information technology, but not models referring to self-care ATs and socially assistive robots. Third, the reviewed models do not primarily focus on older people as potential users. Fourth, and even more important, no overarching theoretical perspective, let alone a psychological one, has guided the reviews of existing AT use models.

In this article, we want to overcome these obstacles by looking at older peoples' use of ATs from an action perspective of lifespan developmental psychology elaborated by Brandtstädter and colleagues (e.g., Brandtstädter, 2001, 2006, 2015). We review from this perspective a broader set of models of AT use stemming mostly from information systems technology, business administration, and management sciences. The major focus is on the extent to which these models consider the relevant internal (mental) and external context of AT use, possible action alternatives to the use of ATs, and autonomous, vicarious, and joint modes of decision-making about AT use.

\section{Action Perspectives in Life-Span Developmental Psychology: Source of Criteria for Reviewing Assistive Technology Use Models}

A European group of life span developmental psychologists (e.g., Brandtstädter, 2001, 2006, 2015; Brandtstädter \& Renner, 1990; Brandtstädter \& Rothermund, 2002) has elaborated an action-theoretical view on human development. It allows us to put AT use of older people in the broader context of the intentional self-regulation of their development, which has a huge potential for a better theoretical understanding of the use of ATs in this population. Brandtstädter has already mentioned that certain ATs can operate as external means of compensation, if a person can no longer perform adequately the usual activities for reaching his or her goals. "If one's own compensatory reserves are not sufficient to achieve compensation goals, external aids can also be used: Apparative prostheses such as hearing aids, visual aids, walking aids, but also modern techniques for monitoring vital functions are examples" (Brandtstädter, 2015, p. 120; Translation by the authors). However, neither he nor his collaborators have further applied this approach to the use of ATs and only a few other researchers have already referred to it (Abrilahij \& Boll, 2018). We now describe the major concepts and assumptions of that action-theoretical view and transfer it to older peoples' use of AT and its alternatives.

\section{Basic Concepts and Assumptions}

\section{Actions in Contexts}

An action is regarded as a behavior (or deliberate nonbehavior) that can be explained with reference to the acting person's goals and beliefs. In particular, the behavior is viewed as intentionally selected from alternative options, which aims to transform situations in accordance with personal representations of the desired future (Brandtstädter, 2006). A basic scheme of action explanation is the "practical syllogism": An actor's desire (a person wants p) and an actor's belief (a person believes that, if I do X, $\mathrm{p}$ will be reached) are the premises, and the conclusion is the resulting action (cf. Brandtstädter \& Rothermund, 2002; Greve, 2001). Within that scheme, explaining the use of an AT has to refer to at least two types of mental representations of the actor. The first type is a desire and the second type is a belief that one can meet this desire by using a certain AT. Action perspectives also include an equifinality principle in assuming that there are often several alternative means to meet a given desire. For instance, an old person can use either technical support or personal support or both to serve his or her welfare.

Action perspectives further include the assumption that individuals pursue multiple goals. The concept of polyvalence highlights the fact that a given action (e.g., using a certain AT) can serve different goals simultaneously (e.g., to live independently, not to burden others) and that a given action can have both intended (and desired) and unintended (and undesired) effects and meanings. Thus, intrapersonal goal conflicts can emerge in the sense that pursuing a certain goal (e.g., being mobile) with certain means (e.g., wheelchair) can frustrate other goals of that person (e.g., not to appear as frail). Action perspectives also take into account that human development takes place in living-together with other people (e.g., relatives). This makes the mutual coordination of the goals and actions of people in human communities an important issue. It also creates the possibility of interpersonal goal conflicts between the different persons involved. Thus, a resolution of interpersonal conflicts and perhaps a joint decision making may become an important task.

Most psychological action theories focus exclusively on the "internal context" of action, which involves an individual's mental representations (e.g., desires, beliefs) relevant for acting. In contrast, action perspectives on life-span development as proposed by Brandtstädter $(2001,2006)$ consider also the "external context" of action. This refers to the material, biological and social conditions of acting. Regarding the topic of AT use, we focus on material conditions referring to 
technology and design aspects of ATs and extend biological to include both biological and functional conditions. The term "social conditions" retained its original meaning. All these external context conditions are assumed to influence the actual performance and outcomes of an action, and can help to explain why these outcomes may differ from what a given person has intended.

\section{Intentional Self-Development in Old Age}

The two-process-model by Brandtstädter and collaborators (e.g., Brandtstädter, 2001, 2006, 2015; Brandtstädter \& Renner, 1990; Brandtstädter \& Rothermund, 2002) views self-monitoring, self-evaluation in relation to one's goals and self-regulated corrective actions as essential processes of personal self-regulation of one's development. The model assumes that in response to perceived discrepancies between a person's actual and desired development (which - in older people - may result from diseases and functional declines) evokes a motivational tendency to reduce such discrepancies. This may lead to more concrete focal desires/goals that aim at preventing or reducing discrepancies between actual and desired development. At least three major kinds of actions may follow assimilative coping, depending on perceived instrumental resources of the person. If personal resources are regarded as sufficient, (1) corrective actions will be initiated. However, if the personal resources are considered as insufficient, but still appear as open to improvement, the person may try to increase the chances for reducing the goal discrepancies by (2) searching for information and by improving one's skills through training. If a person regards the situation as unchangeable by own efforts, the person may (3) attempt to manage the situation by using external means to reach one's goals. This may include the use of technological devices (Brandtstädter, 2015, p. 120). In addition, he also mentions "prothetic environments" which involve an adaptation of living environments to the capacities of older persons. An additional kind of external means is using support by other person(s). If such attempts repeatedly fail, and goal-related control beliefs as well as hope for improvement dwindle, processes of flexible goal adaptation to the available resources (accommodative coping) will follow.

He further considers frustration (and fulfillment) of nonfocal goals through performing a certain action which we apply here to an older person's use of ATs. "Non-focal desires/goals" may refer to features, which ATs should or should not have or they refer to additional benefits or disadvantages, which the use of ATs should or should not cause. Positive and negative emotions are assumed to arise in various phases of intentional self-developmental processes depending on the results of an individual's comparison of the actual and desired development and further cognitive elaboration (see Brandtstädter, 2001, 2006).

\section{Implications for Analyzing AT Use and Reviewing AT Use Models}

The action perspectives allow us to derive at least five implications regarding AT use of older people.

(1) AT use is viewed as arising through several mediating steps from perceived discrepancies between a person's actual and desired development, which initiates a general motivation to reduce such discrepancies.

(2) AT use is regarded as one possible kind of means for that purpose besides others. Major alternatives are investing more time and energy in one's usual goal pursuing activities, increasing one's knowledge and competencies for goal pursuit (e.g., mental or physical training), adapting one's living environment to one's resources (e.g., housing adjustment), and using personal support (e.g., family and/or professional care).

(3) The model of developmental self-regulation assumes a certain sequence of the use of different means to reduce the goal discrepancies: First, a person may invest more time and energy in the usual activities (e.g., self-care activities, walking) and - if that is not sufficient - may acquire additional knowledge and skills. If that is not successful, he or she may use ATs and/or environmental adaptations, and finally support by others.

(4) Important moderating conditions for using one versus another AT or for using alternative kinds of means instead of ATs are beliefs about the effectiveness of the various means for reaching the given goals.

(5) An old person, who no longer believes that certain means allow reaching his or her goals, will no longer use them and try out other ones. If a person believes that there are no effective means at all, this initiates a completely different process for reducing the discrepancies between actual and desired developmental situation: The person adjusts his or her own goals to what is in his or her reach.

\section{Research Goals}

We use major concepts of action perspectives on human development for reviewing a broad range of existing models of AT use from information system engineering, business, management and other sciences. Our research goals are:

(1) Specify, to what extent the predictor variables of AT use models cover the following facets of the internal context of AT use: (a) Perceived discrepancies between current and desired developmental situation (which could result from functional declines) as a motivation for using ATs or alternative options; (b) Focal desires/ goals and beliefs about means for reaching them as two essential kinds of variables for the explanation of 
actions; (c) Anticipated fulfillments or frustrations of non-focal goals of an older person as a result of his or her use of ATs to pursue a focal goal; (d) Goals of other persons (e.g., family members), that might be met or frustrated by an old person's use of ATs; (e) Variables, that are relevant for the switch from a tenacious pursuit to a flexible adaptation of developmental goals (e.g., goal-related control beliefs); (f) Positive and negative emotions toward AT use.

(2) Determine whether AT use models include in their predictor set the external context of actions (e.g., technological/design, biological/functional, and social conditions).

(3) Determine the kind of action alternatives to AT use (if any) which function as outcome variables in the AT use models (e.g., use of AT1 vs. AT2, use of ATs vs. use of personal care). If certain models should include alternatives to AT use do these models contain assumptions about the sequence of their application?

(4) Determine to what extent the existing AT use models consider a person's decision-making on behalf of an old person or the joint decision making about AT use or alternatives among older adults and persons in their social network.

\section{Research Methods}

\section{Systematic Literature Search}

We performed a systematic literature search in PsycINFO and MEDLINE databases and Google Scholar to identify existing AT use models from various disciplines using a combination of search terms and applying specific inclusion/exclusion criteria. A variety of search terms synonymous with central keywords such as "assistive technologies," "models," and "use" were combined in the search strategy. For assistive technologies, synonymous keywords such as "assistive technology," "assistive device," "assistive aid," "assistive equipment" were combined with OR. The keywords for models "model," "modelling," "theory" as well as "theories," "framework," "approach," and "conceptual model" were also combined with OR. The keywords "utility," "utilisation," "utilization," "usage," and "usability" describing the use of a technology were also combined with OR. Finally these three groups of terms were combined with AND. Moreover, the reference lists of relevant articles were searched to identify more relevant articles. The models identified with this search strategy were selected on the basis of a pre-defined set of inclusion and exclusion criteria (see Table 1). Twenty-three publications met our inclusion criteria. The models that are specific to older people are marked with an asterisk (see Table 2). In comparison to the recent reviews by Alkhwaldi and Kamala (2017) and Lai (2017), we have detected 8 additional models including additional predictors (e.g., perceived company of social entity, awareness of the existence of an AT) which were applied to the use of additional kinds of ATs (see Tables 2 and 3, superscript after the year of publication and the note). The resulting review comprised models of the use of a broad range of ATs (e.g., information and communication technologies, self-care ATs, assistive social robots) and models of AT use that are specific to older people. Models should be applicable for the use of ATs, which support a broad range of activities as contained in the International Classification of Function, Disability and Health (ICF) (e.g., self-care activities, social interactions). We excluded articles not related to that topic and articles published in other languages than English.

\section{Description, Classification, and Evaluation of Models}

First, we described the included models with respect to the disciplinary background, the types of ATs covered, the predictor variables referring to the internal and external

Table 1. Inclusion and exclusion criteria for models of AT use versus non use

\begin{tabular}{ll}
\hline Inclusion criteria & Exclusion criteria \\
\hline $\begin{array}{l}\text { Models constructed to predict/explain specifically the use } \\
\text { versus non-use of ATs }\end{array}$ & $\begin{array}{l}\text { Models constructed to predict/explain specifically other behaviors } \\
\text { than use versus non-use of ATs }\end{array}$ \\
$\begin{array}{l}\text { General model of behavior that has been applied by researchers } \\
\text { to predict/explain use/non-use of ATs }\end{array}$ & General models of behavior not (yet) applied by researchers to predict/ \\
Model of AT use/non-use is a theoretical model illustrated by & Model of AT use/non-use is a purely empirical/statistical model for \\
scheme of the model components and their relationships & predicting AT use/ non-use (e.g., a regression model) \\
Models includes actual use/non-use of ATs as behavioral & Models includes only intention to use/not-use AT as outcome variable
\end{tabular}

Models includes actual use/non-use of ATs as behavioral

Unpublished papers; publications in a language other than English 
Table 2. Models of AT use referring to internal (mental representations) and external context variables as predictors

\begin{tabular}{lll}
\hline $\begin{array}{l}\text { Model by name, author(s), and } \\
\text { [disciplinary background] }\end{array}$ & Types of ATs covered & Predictor variables
\end{tabular}

Models referring to mental representations (MR) plus biological/functional (BF) or technology/design (TD) or social (S) aspects of external context

(*) Social cognitive model by Roelands et al. (2002) ${ }^{a}$ [Clinical and developmental psychology]

Unified Theory of Acceptance and Use of Technology by Venkatesh et al. (2003) [Information system engineering]

Unified Theory of Acceptance and Use of Technology 2 by Venkatesh, Thong, and Xu (2012) [Information system engineering]

Technology Acceptance Model 2 by Venkatesh and Davis (2000) [Information system engineering]

A model by Pikkarainen, Pikkarainen, Karjaluoto, and Pahnila (2004) [Management]

A model by Tarhini, El-Masri, Maged, and Serrano (2016) ${ }^{a}$ [Information system technology engineering] Information

Information technology

Information technology

Information technology

Electronic banking technology
MR1. Awareness of existence of ATs AT use

MR2. Attitude toward use

MR3. Self-efficacy

MR4. Subjective norm

MR5. Intention to use

EC-BF1. Functional status

MR1. Performance expectancy AT use

MR2. Effort expectancy

MR3. Perceived social influence

MR4. Perceived facilitating conditions

MR5. Intention to use

MR6. Perceived voluntariness of use

EC-BF1. Experience of device use

EC-BF2. Age

EC-BF3. Gender

MR1. Performance expectancy AT use

MR2. Effort expectancy

MR3. Perceived social influence

MR4. Perceived facilitating conditions for AT use

(resources, knowledge, personal help)

MR5. Perceived price value

MR6. Perceived enjoyment; Hedonic factor

MR7. Perceived habits to use an AT

MR8. Intention to use

EC-BF1. Age

EC-BF2. Gender

EC-BF3. Prior use experience

MR1. Perceived usefulness AT use

MR2. Perceived ease of use

MR3. Subjective norm

MR4. Perceived positive image of using

MR5. Belief regarding job relevance of AT

MR6. Perceived output quality of system

MR7. Perceived result demonstrability

MR8. Perceived voluntariness of AT use

MR9. Intention to use

EC-BF1. Experience of device use

MR1. Perceived ease of use AT use

MR2. Perceived usefulness

MR3. Perceived enjoyment; Hedonic factor

MR4. Perceived trust in AT use

MR5. Sufficient amount of information about AT

EC-TD1. Quality of internet connection

MR1. Performance expectancy

AT use

MR2. Effort expectancy

MR3. Perceived social influence

MR4. Perceived credibility of AT use

MR5. Perceived facilitating conditions for AT use 
Table 2. (Continued)

Model by name, author(s), and [disciplinary background]

Technology Acceptance Model by Davis
(1985) [Information system engineering]

(1985) [Information system engineering]

(*) Almere Model by Heerink et al. $(2010)^{a}$ [Information system engineering]

(*) A model by Chen and Chan (2014) [Engineering]

Model of PC Utilization by Thompson et al. (1991) [Information system engineering]
Types of ATs covered

Predictor variables

Action variables

MR6. Intention to use

EC-TD1. Task technology fit

Information MR1. Perceived usefulness

technology MR2. Perceived ease of use

AT use

MR3. Attitude toward use

EC-TD1. External variables (design features)

Assistive social robots

MR1. Perceived usefulness

MR2. Perceived ease of use

AT use

MR3. Perceived social influence

MR4. Perceived enjoyment; Hedonic factor

MR5. Attitude toward use

MR6. Perceived trust in AT use

MR7. Perceived adaptivity to changing conditions of user

MR8. Anxiety toward use

MR9. Perceived company of social entity

MR10. Perceived sociability of robot

MR11. Intention to use

EC-S1. Facilitating conditions

Technologies for

MR1. Self-efficacy

MR2. Anxiety toward use ("Gerontechnology anxiety")

AT use

MR3. Perceived ease of use

MR4. Perceived usefulness

MR5. Attitude toward use

EC-S1. Facilitating conditions (available help,

financial resources, accessibility, social influences)

Information

technology
MR1. Positive affect toward use

MR2. Perceived social influence

MR3. Perceived complexity of use

MR4. Perceived job-fit

MR5. Perceived long-term consequence (flexibility to change jobs, opportunity for more meaningful work)

EC-S1. Facilitating conditions (availability of guidance, instruction, personal help)

\footnotetext{
Models referring to mental representations (MR) plus biological/functional (BF) and technology/design (TD) or biological/functional (BF) and social (S) or technology/design (TD) and social (S) aspects of external context

A model by Al-Somali et al. (2009) [Information system engineering]

\begin{abstract}
Information technology
\end{abstract}

MR1. Awareness of existence of ATs

MR2. Self-efficacy

MR3. Attitude toward use

MR4. Perceived social influence

MR5. Perceived trust in AT use

MR6. Attitude toward change from traditional banking

MR7. Perceived usefulness

MR8. Perceived ease of use

MR9. Intention to use

EC-BF1. Age

EC-BF2. Gender

EC-BF3. Education

EC-BF4. Income

EC-TD1. Quality of internet connection

AT use
} 
Table 2. (Continued)

Model by name, author(s), and [disciplinary background]

Technology Acceptance Model 3 by Venkatesh and Bala (2008) [Information system engineering]

Model by Triandis $(1980)^{a}$ [Social Psychology]

Innovation diffusion theory by Rogers (1983) [Sociology]

Integrating model of TTF and UTAUT by Zhou, Lu, and Wang (2010) [Information system engineering]

Decomposed theory of planned behavior by Taylor and Todd (1995a) [Business]
Types of ATs covered

Information

technology

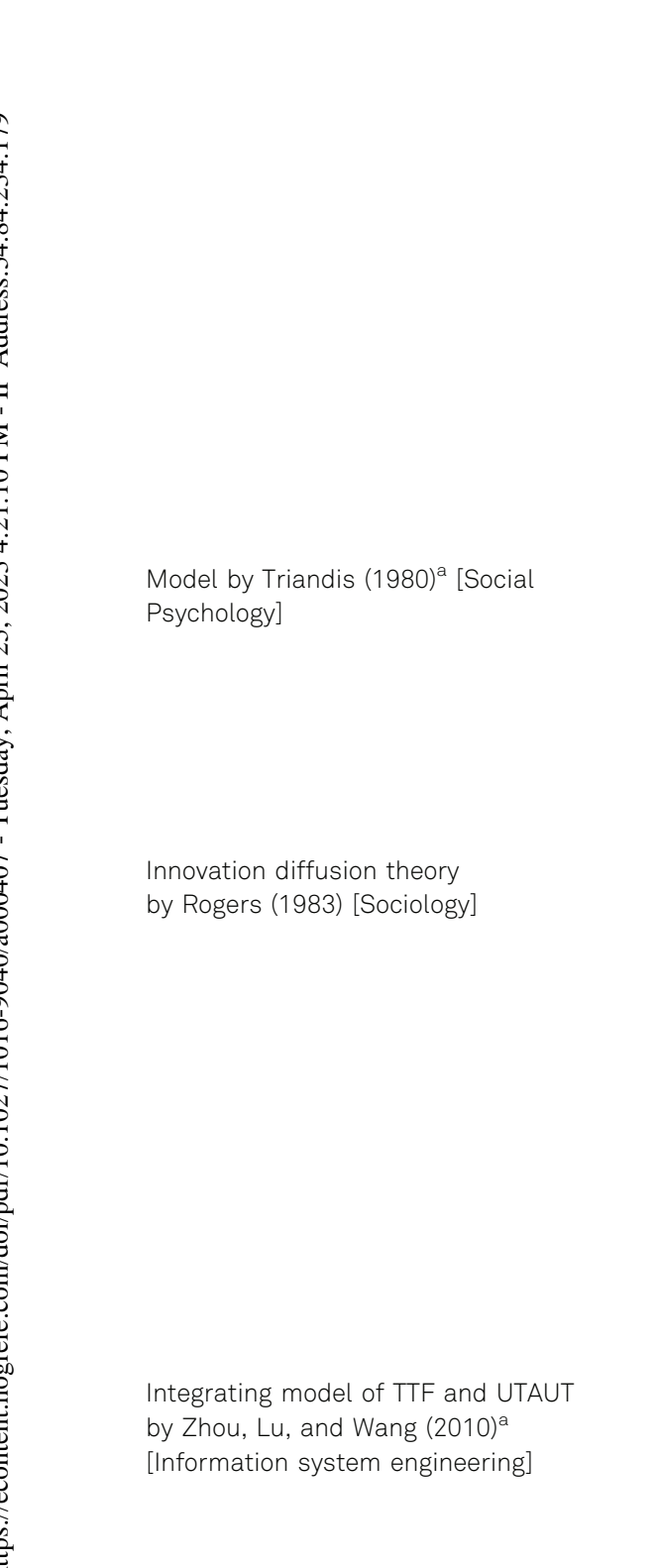

Information technology

Information technology (computer resource center)
Predictor variables

Action variables

MR1. Belief regarding job relevance of AT

MR2. Perceived output quality of system

MR3. Perceived result demonstrability

MR4. Perceived enjoyment

MR5. Perceived usefulness

MR6. Perceived ease of use

MR7. Subjective norm

MR8. Perceived image

MR9. Self-efficacy

MR10. Perceived facilitating conditions for AT use

MR11. Anxiety toward use

MR12. Perceived voluntariness of AT use

MR13. Intention to use

MR14. Perceived computer playfulness

EC-BF2. Experience of device use

EC-TD1. Objective usability

MR1. Attitude toward behavior

MR2. Perceived consequence

MR3. Perceived social norms

MR4. Positive and negative affect toward behavior

MR5. Intention to behave

EC-BF1. Habit of performing behavior

EC-S1. Facilitating conditions (e.g., access)

MR1. Perceived relative advantage compared to precursor AT

MR2. Perceived compatibility with social norms and past experience

MR3. Perceived complexity

MR4. Perceived triability of AT

MR5. Perceived observability of results

EC-BF1. Socioeconomic characteristics

EC-BF2. Personality

EC-BF3. Communication behavior

EC-S1. Change agent contact

EC-S2. Communication channels (mass media, interpersonal channel)

MR1. Effort expectancy

MR2. Performance expectancy

MR3. Perceived facilitating conditions for AT use

MR4. Perceived social influence

EC-TD1. Technology characteristics (ubiquity, immediacy, security)

EC-TD2. Task technology fit (fit between mobile payment task requirements and mobile banking functions)

EC-S1. Task requirements (ubiquitous account management, money transfer and remittance, realtime account information inquiry)

MR1. Attitude toward use

AT use

MR2. Perceived usefulness

MR3. Perceived ease of use
AT use $e^{b}$

AT use

AT use

AT use 
Table 2. (Continued)

Model by name, author(s), and [disciplinary background] Types of ATs covered Predictor variables Action variables

\begin{tabular}{|c|c|c|c|}
\hline & & MR4. Perceived compatibility & \\
\hline & & MR5. Subjective norm & \\
\hline & & MR6. Perceived behavioral control & \\
\hline & & MR7. Self-efficacy & \\
\hline & & MR8. Intention to use & \\
\hline & & EC-TD1. Technology compatibility & \\
\hline & & EC-S1. Peer influence & \\
\hline & & EC-S2. Superior's influence & \\
\hline & & EC-S3. Resource facilitating conditions (time, money) & \\
\hline Models referring to mental representa & s (MR) plus bio & $\begin{array}{l}\text { unctional (BF) and technology/design (TD) and social ( } \\
\text { context }\end{array}$ & cts of external \\
\hline $\begin{array}{l}\text { Technology to performance chain by } \\
\text { Goodhue and Thompson (1995) }\end{array}$ & $\begin{array}{l}\text { Information } \\
\text { technology }\end{array}$ & $\begin{array}{l}\text { MR1. Perceived consequence } \\
\text { MR2. Perceived social norms }\end{array}$ & AT use \\
\hline [Information system engineering] & & MR3. Affect toward use (valence not specified) & \\
\hline & & $\begin{array}{l}\text { MR4. Perceived performance impact (effectiveness, } \\
\text { productivity and job performance) }\end{array}$ & \\
\hline & & EC-BF1. Habit & \\
\hline & & $\begin{array}{l}\text { EC-BF2. Individual characteristics (training, } \\
\text { computer experience, motivation) }\end{array}$ & \\
\hline & & EC-TD1. Task technology fit & \\
\hline & & EC-TD2. Technology characteristics & \\
\hline & & EC-S1. Feedback by others & \\
\hline & & EC-S2. Task requirements & \\
\hline & & EC-S3. Facilitating conditions & \\
\hline $\begin{array}{l}\text { Model of technology uptake by Schulz } \\
(2013)^{a} \text { [Social and developmental }\end{array}$ & $\begin{array}{l}\text { Quality of life } \\
\text { technologies }\end{array}$ & $\begin{array}{l}\text { MR1. Perceived violation of privacy } \\
\text { MR2. Perceived inefficiency }\end{array}$ & AT use \\
\hline psychology] & & MR3. Perceived training requirement & \\
\hline & & MR4. Perceived reduced social interaction & \\
\hline & & MR5. Perceived maintenance requirements & \\
\hline & & MR6. Perceived personal financial costs & \\
\hline & & MR7. Perceived stigma & \\
\hline & & MR8. Perceived enhanced functioning & \\
\hline & & MR9. Perceived autonomy/independence & \\
\hline & & MR10. Perceived reduced burden to others & \\
\hline & & MR11. Perceived better health & \\
\hline & & MR12. Perceived entertainment & \\
\hline & & MR13. Perceived personal cost savings & \\
\hline & & MR14. Perceived enhanced safety & \\
\hline & & EC-BF1. Age & \\
\hline & & EC-BF2. Gender & \\
\hline & & EC-BF3. Education & \\
\hline & & EC-BF4. Income & \\
\hline & & EC-BF5. Health/functional status & \\
\hline & & EC-BF6. Experience with technology & \\
\hline & & EC-BF7. Personality & \\
\hline & & $\begin{array}{l}\text { EC-BF8. Sensory/perceptual, cognitive, } \\
\text { motor capabilities }\end{array}$ & \\
\hline & & EC-TD1. Ease of use & \\
\hline & & EC-TD2. Esthetics & \\
\hline & & EC-TD3. Engagement (fun factor) & \\
\hline
\end{tabular}


Table 2. (Continued)

Model by name, author(s), and

[disciplinary background]

Types of ATs covered

Predictor variables

Action variables

Table 3. The models of AT use referring exclusively to internal context (mental representations) variables as predictors

\begin{tabular}{lll}
\hline $\begin{array}{l}\text { Model by name, author(s), and } \\
\text { [disciplinary background] }\end{array}$ & Types of ATs covered & Predictor variables
\end{tabular}

Note. The models that are specific to older people are identified with an asterisk (*). MR1 to MRn $=$ Mental Representations 1 to Mental Representations $n$. We have specified the original variable designations if they were not clear in relation to the description of users' mental representations (as opposed to external context conditions) by adding "perceived" to the label. We also specified the content of mental representations when the original labels were not sufficiently clear in this respect. To this end, we have relied on the author's theoretical explanations of the variables and/or on information about the measurement of the variables considered. EC-BF1 to EC-BFn = External Context: Biological/functional conditions 1 to $\mathrm{n}$; EC-TD1 to EC-TDn = External Context: Technological/design conditions 1-n; EC-S1 to EC-Sn = External Context: Social conditions 1-n.

${ }^{a}$ The model is not covered in the recent reviews by Alkhwaldi and Kamala (2017) and/or Lai (2017). ${ }^{\text {T}}$ The model by Triandis (1980) refers to the prediction of a behavior in general. Here we specified the behavior as use of AT.

[disciplinary background]

Models exclusively referring to beliefs and emotions

Social Cognitive Theory by Information technology (computer) MR1. Self-efficacy

AT use

Compeau, Higgins, and Huff (1999)

[Information system engineering]

MR2. Performance outcome expectations

MR3. Personal outcome expectations

MR4. Positive affect toward use

MR5. Anxiety toward use

Models exclusively referring to beliefs and attitudes

Theory of Reasoned Action by Fishbein and Ajzen (1975) [Social Psychology]

Theory of Planned Behavior by Ajzen (1991) [Social Psychology]

A model by Suh and Han (2002) [Management]

Information technology (Internet banking)

Information technology (computer resource center)

$\begin{array}{lll} & \text { MR1. Attitude toward behavior } & \text { AT use } \\ & \text { MR2. Subjective norm } & \\ & \text { MR3. Intention to behave } & \text { AT use } \\ & \text { MR1. Attitude toward behavior } & \\ & \text { MR2. Subjective norm } & \\ & \text { MR3. Perceived behavioral control } & \\ & \text { MR4. Intention to behave } & \text { AT use } \\ \text { Information technology (Internet } & \text { MR1. Attitude toward use } & \\ \text { banking) } & \text { MR2. Perceived ease of use } & \\ & \text { MR3. Perceived usefulness } & \text { AT use } \\ & \text { MR4. Perceived trust in AT use } & \\ \text { Information technology (computer } & \text { MR2. Intention to use } & \\ \text { resource center) } & \text { MR2. Sttitude toward use } & \\ & \text { MR3. Perceived behavioral control } & \\ & \text { MR4. Perceived usefulness } & \\ & \text { MR5. Perceived ease of use } \\ & \text { MR6. Intention to use } & \end{array}$

Composed-Technology Acceptance Model - Theory of Planned Behavior by Taylor and Todd (1995b) [Business]

Note. MR1 to MRn = Mental Representations 1 to Mental Representations $n$. We have specified the original variable designations if they were not clear in relation to the description of users' mental representations (as opposed to external context conditions) by adding "perceived" to the label. We also specified the content of mental representations when the original labels were not sufficiently clear in this respect. To this end, we have relied on the author's theoretical explanations of the variables and/or on information about the measurement of the variables considered. ${ }^{2}$ The model is not covered in the recent

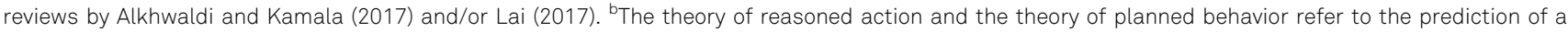
behavior in general. Here we specified the behavior as use of AT. 


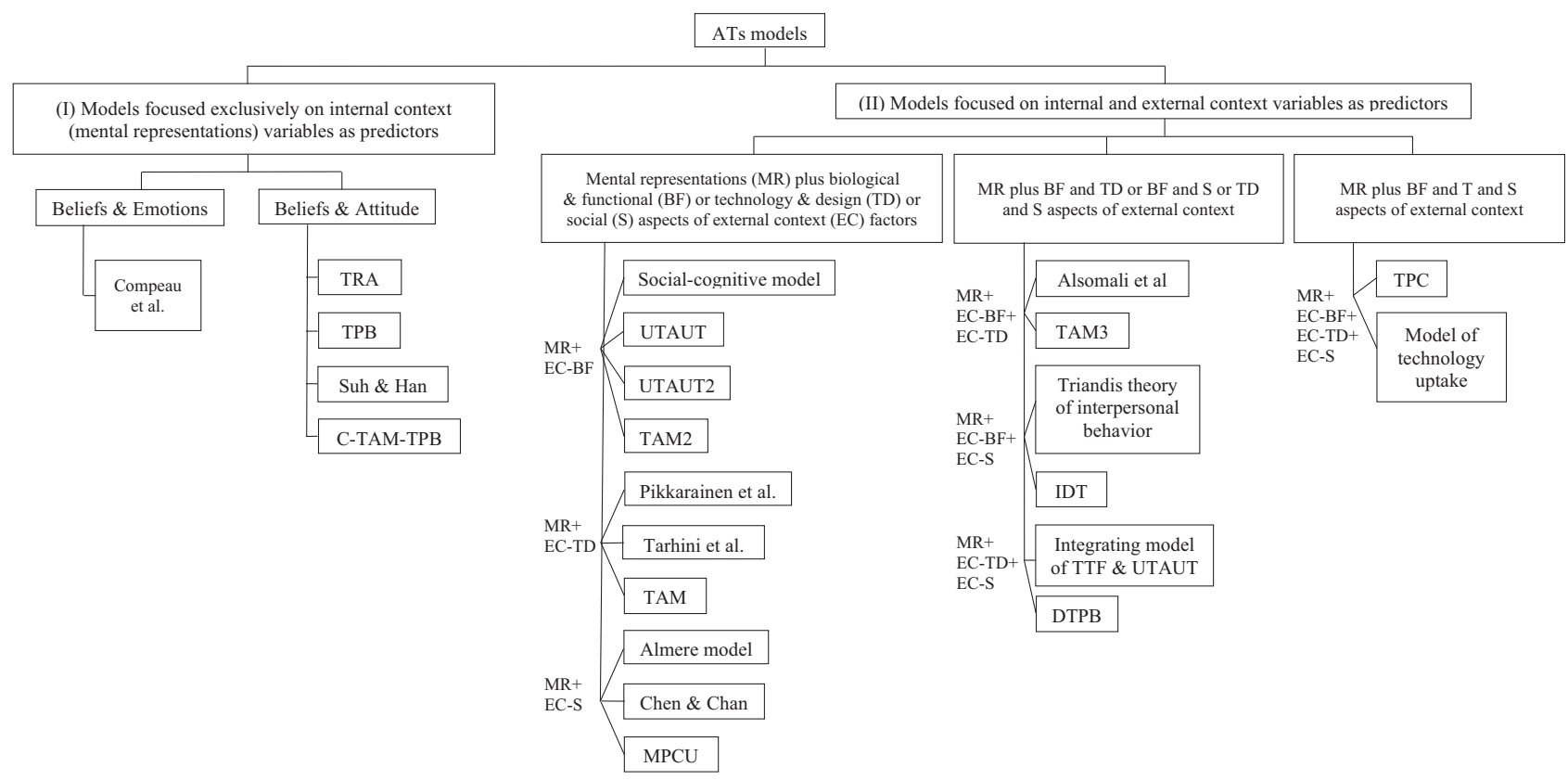

Figure 1. Classification of AT use models. C-TAM-TPB = composed technology acceptance model theory of planned behavior; DTPB = decomposed theory of planned behavior; IDT = innovation diffusion theory; MPCU = model of PC use; TAM = technology acceptance model; TPB = theory of planned behavior; TPC = technology to performance chain; TRA = theory of reasoned action; TTF = task technology fit model; UTAUT = unified theory of acceptance and use of technology.

context of AT use, and the action variables considered in relation to AT use. Second, we sorted the models into two major groups. The first group encompasses those five models that entailed only mental representations of potential users (e.g., beliefs, attitudes, emotions), that is only "internal context" variables as predictors of AT use (see Table 3). Within this group we further subdivided the models depending on the kind of internal context predictors. The second group comprises 18 AT use models that encompass other predictors, in particular external in addition to internal context variables of AT use (see Table 2). Within this group we further subdivided the models depending on the kind and complexity of external context predictors. The classification of models is illustrated in Figure 1 and is also reflected in the internal subdivision of Tables 2 and 3.

In a next step, we checked whether the internal and external context predictors as well as the action alternatives in relation to AT use meet the abovementioned criteria of an action perspective on human development. For that purpose, the authors first sorted independently the identified internal context (mental representations; MR) predictors in Tables 2 and 3 (3rd column) into four major categories suggested by the action perspective on human development (see Table 4):

(1) initial Motivations for AT use versus non-use,

(2) elements of a basic action explanation (e.g., focal desires/goals and beliefs about effective means),
(3) perceived fulfillment or frustration of non-focal goals, (4) positive versus negative emotions toward AT use, and (5) further mental representations.

An analogous procedure was applied to the external context predictors contained in Table 2 , which were sorted into three major categories:

(1) technological/design,

(2) biological/functional, and

(3) social conditions (see Table 5).

Secondly, we compared the resulting categorizations of both authors. If there were discrepancies, we discussed them to arrive at a consensual categorization.

\section{Results}

\section{Internal Context of AT Use: Mental Representations as Predictors}

Our first research goal was to specify the extent to which the predictor variables of existing AT use models represent the major facets of the internal context of AT use.

\section{Initial Motivations for AT Use}

An action perspective on intentional self-regulation of one's development regards perceived discrepancies between 
Table 4. Internal context variables (mental representations) as predictors in the reviewed AT use models Predictors for Use of AT Predictors for Non-Use of AT

(1) Initial motivation for at use versus non-use

(1.1) Perceived discrepancies versus matches between actual and desired developmental situation $\varnothing$

$\varnothing$

(1.2) Other motivations

\footnotetext{
${ }^{2,10}$ Awareness of existence of ATs

${ }^{9}$ Sufficient amount of information about AT

${ }^{2}$ Attitude toward change from traditional banking
}

(2) Elements of a basic explanation of actions

\section{(2.1) Focal goals}

\section{$\varnothing$} $\varnothing$

(2.2) Beliefs about ATs as means to achieve versus not to achieve focal goals

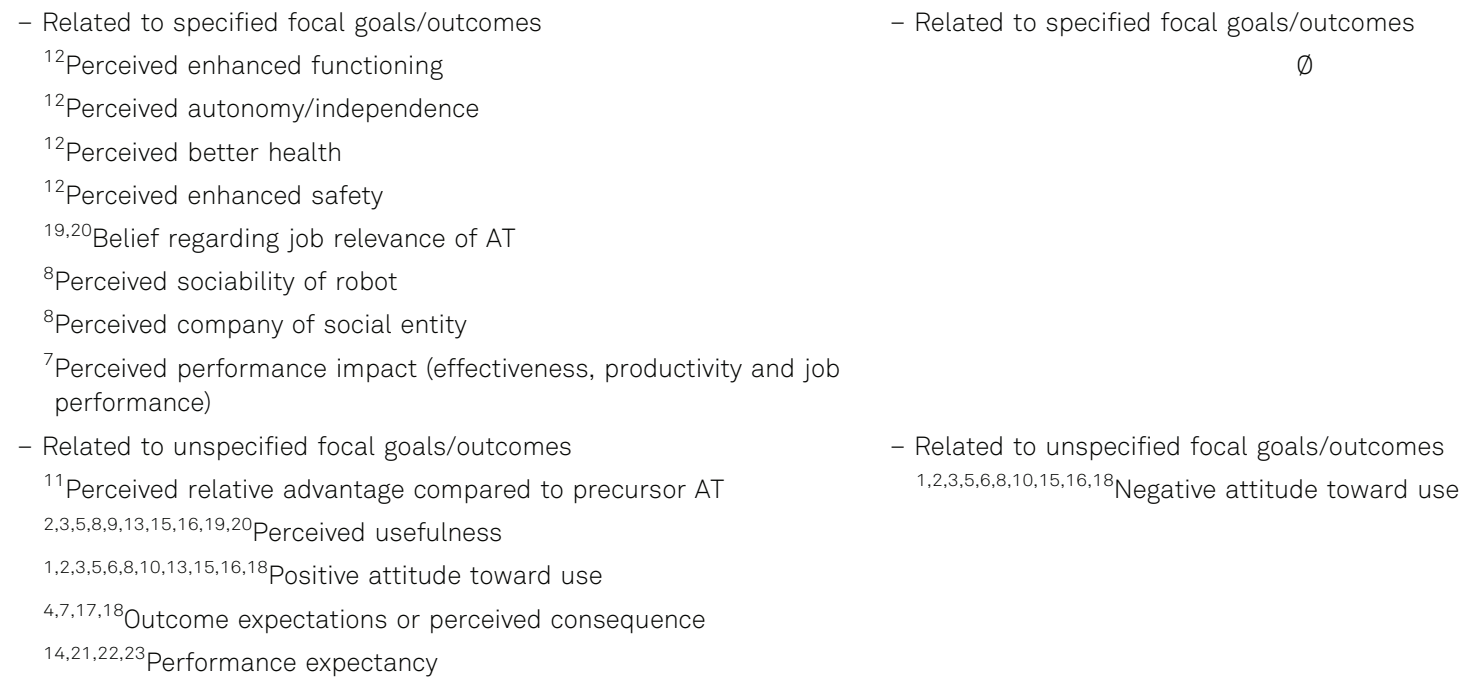

(2.3) Goal-related control beliefs

2,3,4,10,15,19 Perceived low self-efficacy

(2.4) Behavioral intention

$\varnothing$

2,8,10,13,14,15,16,19,20,21,22 Intention to use

(3) Perceived fulfillment versus frustration of non-focal goals

- Related to specified goals/outcomes

${ }^{11}$ Perceived observability of results

${ }^{19,20}$ Perceived result demonstrability

${ }^{19,20}$ Perceived output quality of system

2,3,5,8,9,13,15,16,19,20 Perceived ease of AT use

14,21,22,23 Low effort expectancy

${ }^{14}$ Perceived credibility of AT use

2,8,9,13 Perceived trust in AT use

${ }^{8}$ Perceived adaptivity to changing conditions of user

${ }^{11}$ Perceived triability of AT

${ }^{20}$ Perceived positive image of using an AT

${ }^{22}$ Perceived price value

${ }^{12}$ Perceived personal cost savings

${ }^{12}$ Perceived reduced burden to others

${ }^{19,20,21}$ Perceived voluntariness of AT use

${ }^{17}$ Perceived job-fit
- Related to specified goals/outcomes

${ }^{11,17}$ Perceived complexity

${ }^{12}$ Perceived inefficiency

${ }^{12}$ Perceived maintenance requirement

${ }^{12}$ Perceived personal financial costs

${ }^{12}$ Perceived violation of privacy

${ }^{12}$ Perceived stigma

${ }^{12}$ Perceived training requirement

${ }^{12}$ Perceived reduced social interaction 
Table 4. (Continued)

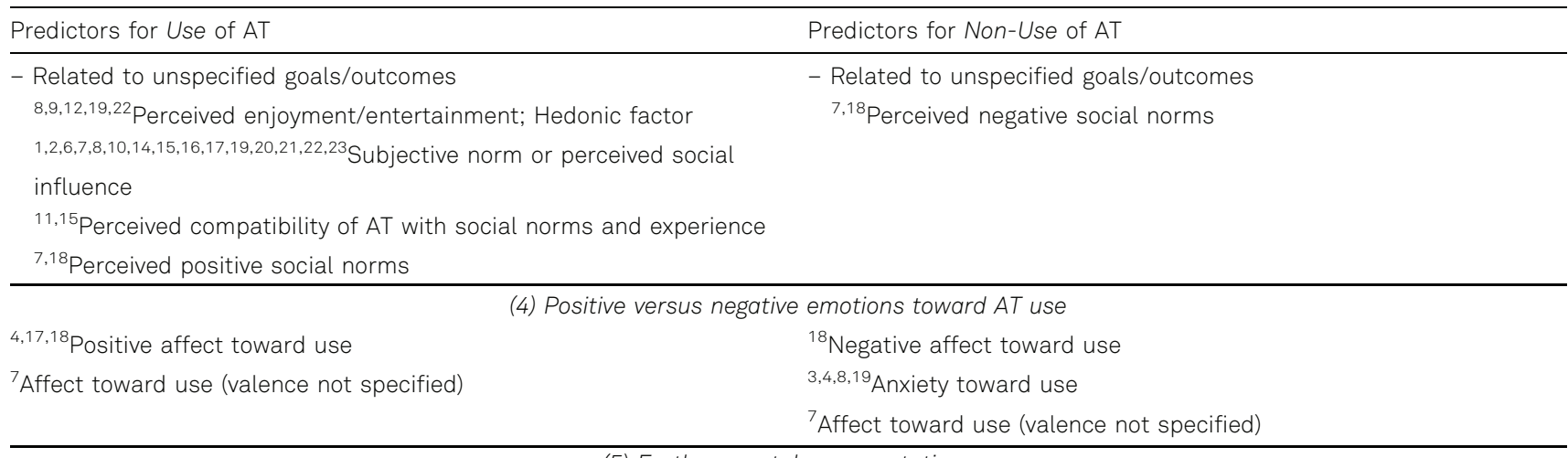

(5) Further mental representations

${ }^{14,19,22,23}$ Perceived facilitating conditions for AT use

$\varnothing$

${ }^{22}$ Perceived habits to use an AT

${ }^{19}$ Perceived computer playfulness

Note. Superscripts before the predictors for AT use or non-use indicate from which authors of AT-use model they stem and this information makes a cross reference to Table 2 and Table 3: ${ }^{1}$ Ajzen (1991), ${ }^{2}$ Al-Somali et al. (2009), ${ }^{3} \mathrm{Chen}$ and Chan (2014), ${ }^{4}$ Compeau et al. (1999), ${ }^{5}$ Davis (1985), ${ }^{6}$ Fishbein and Ajzen (1975), ${ }^{7}$ Goodhue and Thompson (1995), ${ }^{8}$ Heerink et al. (2010), ${ }^{9}$ Pikkarainen et al. (2004), ${ }^{10}$ Roelands et al. (2002), ${ }^{11}$ Rogers (1983), ${ }^{12}$ Schulz (2013), ${ }^{13}$ Suh and Han (2002), ${ }^{14}$ Tarhini et al. (2016), ${ }^{15}$ Taylor and Todd (1995a), ${ }^{16}$ Taylor and Todd (1995b), ${ }^{17}$ Thompson et al. (1991). ${ }^{18}$ Triandis (1980), ${ }^{19} \mathrm{Venkatesh}$ and Bala (2008), ${ }^{20}$ Venkatesh and Davis (2000), ${ }^{21}$ Venkatesh et al. (2003), ${ }^{22}$ Venkatesh et al. (2012), ${ }^{23} \mathrm{Zhou}$ et al. (2010). $\varnothing$ : No relevant predictors included in the models.

actual and desired (developmental) situation as motivating the person to approximate the given situation more closely to the desired one. However, none of the existing AT use models comprised such discrepancies as a predictor. Yet, they contained variables referring to other motivations for AT use (see Table 4). For instance, the Social Cognitive Model by Roelands et al. (2002) and a model by Al-Somali, Gholami, and Clegg (2009) include the awareness of the existence of an AT as predictor of AT use.

\section{Elements of a Basic Action Explanation: Goals in Combination With Beliefs About Efficient Means}

As emphasized in the theoretical section, an explanation of AT use as an action has to refer to at least two major types of mental representations, namely a desire/goal in combination with a belief that certain ATs are efficient means for reaching these goals (cf. Abrilahij \& Boll, 2019). An inspection of Tables 2 and 3 (3rd column) reveals that none of the reviewed models of AT use encompassed a combination of these two interrelated variables in its predictor set. More importantly, the reviewed models did not even comprise any desires or goals as distinct variables among their predictors (see Table 4, Section 2.1). However, most of the models encompassed the other essential element required for an explanation of AT use as an action, namely beliefs about ATs as possible means for reaching focal goals (see Table 4, Section 2.2). For instance, the Almere Model by Heerink et al. (2010) contains a very specific belief about the extent to which a robot can provide the desired social company (e.g., perceived sociability of robot). The model of technology uptake by Schulz (2013) entails several beliefs about the extent to which an AT can improve certain facets of a potential user's developmental situation (e.g., perceived enhanced functioning, perceived autonomy or independence, perceived better health, perceived enhanced safety). Other models of AT use (e.g., Technology Acceptance Model by Davis, 1985; Technology Acceptance Model 2 by Venkatesh \& Davis, 2000; Unified Theory of Acceptance and Use of Technology by Venkatesh, Morris, Davis, \& Davis, 2003) include rather abstract beliefs that an AT can serve the user's goals whatever their content may be (e.g., perceived usefulness, performance expectancy, outcome expectations or perceived consequences).

According to the two-process-model of personal selfregulation of development explained above an erosion of goal-related control beliefs initiates the switch from tenacious goal pursuit to flexible goal adaptation. Several existing models of AT use entail related variables namely perceived high or low self-efficacy and perceived behavioral control as predictors of use or non-use of AT. However, these models do not link low self-efficacy and perceived low behavioral control with a transition to processes of flexible goal adaptation.

\section{Perceived Fulfillment Versus Frustration of Non-Focal Goals}

Action perspectives on human development point to the polyvalence of human actions, namely, that a certain action (e.g., using a walker) can serve several goals (e.g., to be mobile, not be a burden to others), but may - at the 
Table 5. External context variables as predictors in the reviewed AT use models

\begin{tabular}{l}
\hline Predictors for Use of AT \\
\hline${ }^{3}$ Design features of AT (objective design characteristics: menus, icons, \\
touch screens) \\
${ }^{9}$ Esthetic features of AT \\
${ }^{9}$ Engaging features (fun factor) of AT \\
${ }^{4,10,18}$ Match between technology and task requirements \\
${ }^{9}$ Match between technology and sensory/perceptual, cognitive, and motor \\
abilities/system-user fit \\
${ }^{4,9,11,14,18}$ Objective usability (ease of use, functionality, controllability, \\
reliability, safety, compatibility, ubiquity, immediacy) \\
${ }^{1,6}$ Quality of internet connection
\end{tabular}

${ }^{1,6}$ Quality of internet connection

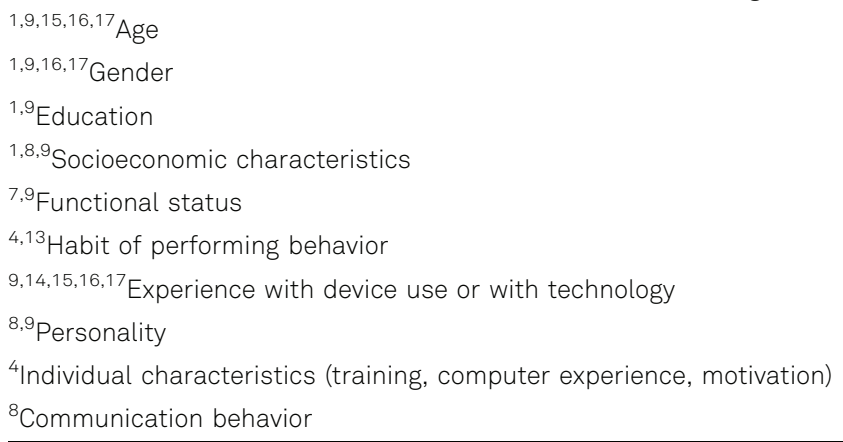

Note. Superscripts before the predictors for AT use or non-use indicate from which AT-use model they stem and this information makes a cross reference to Table 2: ${ }^{1}$ Al-Somali et al. (2009), ${ }^{2}$ Chen and Chan (2014), ${ }^{3}$ Davis (1985), ${ }^{4}$ Goodhue and Thompson (1995), ${ }^{5} \mathrm{Heerink}$ et al. (2010), ${ }^{6} \mathrm{Pikkarainen}$ et al. (2004), ${ }^{7}$ Roelands et al. (2002), ${ }^{8}$ Rogers (1983), ${ }^{9}$ Schulz (2013), ${ }^{10}$ Tarhini et al. (2016), ${ }^{11}$ Taylor and Todd (1995a), ${ }^{12}$ Thompson et al. (1991). ${ }^{13}$ Triandis (1980),

${ }^{14}$ Venkatesh and Bala (2008), ${ }^{15}$ Venkatesh and Davis (2000), ${ }^{16}$ Venkatesh et al. (2003), ${ }^{17}$ Venkatesh et al. (2012), ${ }^{18} \mathrm{Zhou}$ et al. (2010).

same time - frustrate one or more other goals (e.g., not to appear as frail, to save costs). Table 4 (Section 3, left half) reveals, that several models include beliefs about AT use, which may fulfill goals of a good usability of ATs, either very specific ones (e.g., perceived observability of results, result demonstrability, output quality of system) or more general ones (e.g., ease of use, low effort, adaptivity to changing conditions of the user). Further predictors refer to positive economic attributes of ATs (e.g., perceived high price value) or positive consequences of AT use in social interactions or relationships (e.g., perceived positive image of using an AT). Other beliefs have even more general contents and are related to a fulfillment of even more abstract desires (e.g., perceived enjoyment; perceived compatibility with social norms). The right half of Section 3 of Table 4 refers to perceptions implying either a violation of goals of a good usability (e.g., perceived complexity, maintenance requirement) or a frustration of still other desires possibly relevant for older people (e.g., perceived violation of privacy, perceived stigma, perceived reduction of social interaction).

\section{Positive and Negative Emotions Toward AT Use}

A fourth group of predictors contained in seven AT use models consists of emotion variables with different degrees of specification (see Table 4, Section 4). A first one is rather global and is called "affect toward use" without any indication of the valence of the affect. Two other variables provide this information (positive affect or negative affect toward AT use), but refrain from finer distinctions between individual emotions. A final variable refers to one specific emotion, namely "anxiety toward AT use." 


\section{External Context of AT Use: Technological/ Design, Biological/Functional, and Social Conditions}

Our second research goal was to determine the external context variables (e.g., technological/design, biological/ functional, and social conditions) which are comprised in the predictor sets of the reviewed AT use models. Figure 1 (left main branch and its two sub-branches) and Table 3 (3rd column) show that 5 out of 23 models include only internal (mental) context and no external context predictors of AT use at all. However, Figure 1 (right main branch and its three sub-branches) and Table 2 ( 3 rd column) also show that 18 out of 23 models include external in addition to internal context predictors. Figure 1 and Table 2 reveal that two models provided the most comprehensive coverage by including all three kinds of external context factors, namely, technological/design (TD), biological/functional (BF), and social (S) conditions (Technology to performance chain by Goodhue \& Thompson, 1995; Model of technology uptake by Schulz, 2013). Six other models contained only two kinds of external context conditions in different combinations (BF and TD, BF and S, TD and S) and 10 other models contained just one kind of external context conditions (either BF or TD or S). Across all models "match between technology and tasks requirements" and "objective usability" were the most frequently mentioned "technology and design conditions," "age," and "experience with device use or with technology" the most mentioned "biological/functional conditions" and "facilitating social conditions" the most commonly used "social condition" (see Table 5).

\section{Action Alternatives in Relation to AT Use and Different Modes of Decision Making}

Our third research goal was to examine which action alternatives in relation to AT use the reviewed models contain. Tables 2 and 3 (4th column: "action variables") reveal that all the models comprised only the amount of AT use as relevant variable. No model of AT use entails the choice between the use of two or more different ATs as outcome variable. However, the authors of the social cognitive model (Roelands et al., 2002) mentioned in passing that someone could use an AT in combination with personal care as mutually supplementing means. Moreover, the author of the technological uptake model (Schulz, 2013) notes casually that the perceived costs of ATs are appraised in comparison to alternative solutions such as training, maintenance requirements or human assistance. Yet, they have not systematically recognized such options as an important alternative or complement to the use of ATs. Because none of the AT use models included one or more action alternatives beyond AT use, the issue of the sequence of their implementation to improve one's developmental situation could not arise.

Our fourth research goal was to determine whether the reviewed AT use models consider a decision-making on behalf of another person or a joint decision making about the use or non-use of ATs among older people and others in their social network. It turned out that all these models refer only to decision or actions of individual users as outcome variables and not to deciding on behalf of others or joint decision-making.

\section{Discussion}

In this article, we reviewed 23 existing models of the use of ATs from an action perspective of life-span developmental psychology. Compared to the latest reviews by Alkhwaldi and Kamala (2017) and Lai (2017), eight important additional models were covered. The scope of application of these models extends to additional kinds of ATs beyond information technologies, namely, assistive social robots and self-care ATs. The theoretical perspective guiding our review allowed us to detect several limitations of existing AT use models. We discuss the background of these gaps, possibilities of a more comprehensive modeling of AT use, and practical implications for developmental counseling and design of ATs.

\section{Implications of Major Findings}

\section{Internal Context of AT Use}

All 23 reviewed models include various internal context factors (mental representations). However, all of them neglect specific predictor variables referring to perceived discrepancies between the actual and the desired developmental situation as well as to a resulting motivation to reduce them. Such a lack may be due to the disciplinary background from which most of these models emerged (e.g., information system engineering, business, and management sciences) which lack a life-span developmental perspective. It further turned out that none of the 23 reviewed models employs desires of potential users in combination with their beliefs about effective means to satisfy them in line with the most basic scheme of action explanation (cf. Abrilahij \& Boll, 2019; Greve, 2001). Fortunately, our review identified several variables that at least implicitly refer to certain desires or goals of potential users, which we now make explicit. A first group of goals can be derived from beliefs about ATs as means to achieve focal goals. Most of them refer to an improvement of major facets of a person's developmental situation (e.g., enhanced 
functioning, autonomy, health, and safety). A second group of goals can be inferred from certain perceptions of ATs that constitute a fulfillment or frustration of relevant non-focal desires or goals. A first subset refers to good usability, either to specific aspects (e.g., observability of results, result demonstrability, output quality of system, little maintenance requirement) or to wider aspects of use (e.g., low complexity, ease of use, low effort, adaptivity to changing conditions of the user). A second subset includes economic desires or goals (e.g., low financial costs, high price value). A third subset contains desires and goals related to social interactions or relationships, either ego-centred (e.g., positive image of using an AT, avoidance of stigma, preserving privacy) or altruistic (e.g., reducing burden to others). However, the list of desires inferred from AT use models does not cover all the relevant desires. A recent metasynthesis of qualitative studies on subjective reasons for using or not using ATs (Abrilahij \& Boll, 2019) has identified additional ones (e.g., to please a person who suggested an AT; to receive social support) and still further reasons might be detected in the future research (e.g., desire to avoid health risks).

\section{External Context of AT Use}

Action perspectives on human development suggest, that the use of ATs is a function of both the internal and external context the last of which including technological/ design, biological/functional and social conditions of AT use. However, 5 of the 23 AT use models consider no external context conditions at all. They thus lack an important subset of conditions that are required for a comprehensive explanation of AT use or non-use and for developing ATs with a better fit to the given tasks, the remaining resources of older people as potential users, other aspects of the usability and further conditions that facilitate the use of ATs. More complete in one or more of these respects are the remaining 18 of the 23 models that include external context factors in addition to internal context factors.

A comparison of the two major kinds of context factors (Tables 4 and 5) reveals that some variables of the external context have counterparts in the internal context. This applies, for example, to "objective usability" and "perceived ease of use," "facilitating conditions" and "perceived facilitating conditions," "social influence" and "perceived social influence," "match between technology and task requirement" and "perceived usefulness." A consideration of such corresponding variables raises the question to what extent the external context and its mental representation converge or diverge. It may well be, that important aspects of the external context are not mentally represented in a potential user. Conversely, a mental representation may have a content that does not correspond to anything in the external context. Such discrepancies can lead to unwanted and unexpected negative effects of AT use or to the absence of any positive effects that could in principle be achieved by AT use. Future research may determine why such discrepancies occur and how they can be overcome if they have dysfunctional consequences.

\section{Action Alternatives to the Use of ATs}

The reviewed models of AT use consider only the amount of AT use as an action variable. That is a much-reduced view of the possible ways of acting in the face of perceived discrepancies between actual and desired development due to functional declines and limitations of activities. It ignores the many important options that an action perspective on human development suggests (e.g., trying harder, acquiring new knowledge and competencies, adapting one's living environment, using personal support). The AT use models reviewed neither contain perceived discrepancies between current and desired developmental situations nor a general motivation to reduce such discrepancies as essential variables. Thus, there is no conceptual starting point to systematically include in the models alternative means to the use of AT.

A neglect of these alternatives may strengthen the view that using an AT is a purpose in itself and unquestionably given. Socio-cultural factors may promote such a narrow focus. For producers of ATs who have a strong interest in selling them, ignoring alternatives to AT use is very functional. This may apply as well to researchers from the aforementioned disciplines to the extent that they share their view. However, this may contradict the interests of older people who have to cope with developmental losses. They are presumably more concerned with finding the most effective means of improving their situation. Only in some cases, ATs may be optimal; in other cases, alternative means might be better.

\section{Individual Versus Joint Decision-Making About AT Use and Alternative Avenues of Action}

All reviewed models conceive of AT use or non-use as an act of an individual potential user. This neglects that in some cases family members decide about the acquisition or use of an AT on behalf of an old person who may not be able or may not receive the opportunity to make such a decision him- or herself. This also ignores that in other cases an old person and family member(s) decide together on the acquisition and use of an AT. These limitations restrict the value of AT use models for practical applications in the design and marketing of ATs and in developmental counseling regarding AT use and alternative means. In contrast, family decisions on AT use by disabled children received slightly more consideration (Parette, VanBiervliet, \& Hourcade, 2000). 


\section{Limitations of Present Review}

We provided a theory guided review of existing AT use models, which resulted in a plethora of findings about the limitations of these models and provided new options for further improving them. However, we have not evaluated the predictive value of existing AT use models on the basis of empirical findings, because the number, quality, and comparability of relevant studies is not yet sufficient for such an attempt, let alone for a meta-analysis that meets high quality standards.

We based our review on action perspectives on human development, which allowed us to detect several limitations of the addressed AT use models. However, what are the limitations of the approach we used? Could it have restricted our review and/or further ideas about how to improve the theoretical modeling of AT use? We do not see serious limitations even for cases in which older people can no longer generate the relevant goals and beliefs in such a differentiated and coherent manner that is required for autonomous decision-making about AT use (e.g., due to severe dementia). In such cases, the action-theoretical approach can be applied to those other persons (e.g., guardians), who may decide on behalf of the older person about AT use and its alternatives. However, the modeling of joint decision-making about these matters by older adults and other people in their social networks provides a larger challenge. It requires substantial theoretical extensions of the action perspectives on human development with respect to co-orientation, joint decision-making, and coordinated acting of multiple agents.

\section{Implications for Future Research}

\section{Improved Modeling of AT Use and Alternative Avenues for Action}

Future research on AT use should pay more attention to several facets of the internal and external context of AT use as well as the action alternatives to AT use. To improve the modeling of AT use and its alternatives several new variables should be taken into account. These include:

(1) desires regarding one's developmental situation,

(2) perceived discrepancies between the actual and the desired situation,

(3) emerging focal goals to reduce these discrepancies, and

(4) beliefs about the effectiveness of the major kinds of means for reducing perceived developmental discrepancies.

Finally, external context factors related to the abovementioned internal context factors and that are relevant for the effects of one's actions should also be considered.

\section{Different Modes of Decision Making About AT Use and Its Alternatives}

Decisions about use of ATs (and its alternatives) can be made (1) autonomously by older persons, (2) jointly with other persons, or (3) by other persons on behalf of older persons. Future research tasks will firstly relate to the structure and process of the second and third type of decision making. For example, when it comes to a relative's decision on behalf of an older person, the central variables would be the perceptions, desires, and beliefs of the very person making the decision (e.g., a relative). Increased research efforts should then be directed in particular at the joint decision making process between older persons and their relatives about the use of ATs (or its alternatives), which has been severely neglected up to now. A final research question relates to the conditions under which a change from one of the above-mentioned forms of decision making (e.g., autonomous) to another (e.g., joint) occurs.

\section{Significance for European Research Programs}

Action perspectives on human development strongly emphasize the role of perceptions as well as desires, goals and beliefs of individuals and their close social relationship partners for the acting of older people. It can contribute to strengthening their position as potential users of ATs or other means of dealing with functional declines and activity limitations. There is a considerable need for this, because in the large scale European "Ambient (Active and) Assisted Living - Joint Programme" (AAL-JP) the similar idea that ATs should contribute to the autonomy, social participation, and health of older adults is only one goal besides three others. The AAL-JP attaches also great importance (1) to the development of innovative ATs, (2) to promoting the economic profit of their inventors and producers, and (3) to the function of ATs to reduce public spending on health and social care services (Active Assisted Living Programme, 2019). An action perspective on human development should help to counterbalance the impending predominance of these three interests.

\section{Implications for Practical Applications}

The review of AT use models and the preceding discussion have many implications for practical application such as developmental counseling of older people with functional declines and activity limitations. A counseling based on action perspectives on human developmental includes at least six central steps. Among them are (1) an analysis of the developmental problem, (2) a clarification of involved persons' goals, (3) the dealing with intra- and interpersonal goal conflicts, (4) decision making about means, action planning, and activation of resources, (5) support during the implementation of a decision, and (6) the assistance 
in flexible goal adaptation (Gräser, 2007, 2012). We cordially invite the readers to concretize these steps based on the above information about AT use and its alternatives.

\section{Conclusion}

Applying action perspectives in life-span developmental psychology to AT use enabled us to uncover several conceptual limitations of the reviewed AT use models stemming mostly from information system engineering, business, and management sciences. This gave rise to many impulses for an improved modeling of AT use and related research in general. That referred to internal and external context factors of AT use as well as to several action alternatives regarding AT use. Furthermore, it has sensitized us to the different modes of decision-making about AT use. All this should stimulate future research on the use of AT and its design as well as practical applications (e.g., developmental counseling, training) to better address this complexity. Action perspectives in life-span developmental psychology feel particularly committed to consider the subjective appraisals and concerns of individuals in his or her life world. This complements the views on AT use that other disciplines more concerned with technical innovation, economic profit and budget austerity have. A broader theoretical perspective should also help to integrate findings from neighboring research areas (e.g., on personal elder care). All this should contribute to an improved understanding and better professional solutions for the specific problems of older people and their families.

\section{References}

The reviewed articles that were included are identified with an (*) in the following list.

Abrilahij, A., \& Boll, T. (2018). A systematic review of self-care assistive technologies for aging population. In T. Boll, D. Ferring, \& J. Valsiner (Eds.), Cultures of care in aging (pp. 273-313). Charlotte, NC: Information Age Publishing.

Abrilahij, A., \& Boll, T. (2019). A Qualitative Meta-synthesis of reasons for the use or non-use of assistive technologies in the aging population. GeroPsych, 32, 79-92. https://doi.org/ 10.1024/1662-9647/a000203

Active Assisted Living Programme. (2019). Homepage. Retrieved from https://www.aal-europe.eu

*Ajzen, L. (1991). The theory of planned behavior. Organizational Behavior and Human Decision Processes, 50, 179-211. https:// doi.org/10.1016/0749-5978(91)90020-T

Alkhwaldi, A., \& Kamala, M. (2017). Why do users accept innovative technologies? A critical review of models and theories of technology acceptance in the information system literature. Journal of Multidisciplinary Engineering Science and Technology, 4(8), 7962-7971.
*Al-Somali, S. A., Gholami, R., \& Clegg, B. (2009). An investigation into the acceptance of online banking in Saudi Arabia. Technovation, 29(2009), 130-141. https://doi.org/10.1016/j. technovation.2008.07

Brandtstädter, J. (2001). Entwicklung - Intentionalität - Handeln [Development-intentionality-action]. Stuttgart, Germany: Kohlhammer.

Brandtstädter, J. (2006). Action perspectives on human development. In R. M. Lerner (Ed.), Handbook of Child Psychology: Theoretical models of human development (6th ed., Vol. 1, pp. 516-568). New York, NY: Wiley.

Brandtstädter, J. (2015). Positive Entwicklung. Zur Psychologie gelingender Lebensführung [Positive development: On the psychology of a successful life management]. Heidelberg, Germany: Springer Spektrum.

Brandtstädter, J., \& Renner, G. (1990). Tenacious goal pursuit and flexible goal adjustment: Explication and age-related analysis of assimilative and accommodative strategies of coping. Psychology and Aging, 5, 58-67.

Brandtstädter, J., \& Rothermund, K. (2002). The life-course dynamic of goal pursuit and goal adjustment: A two-processes framework. Developmental Review, 22, 117-150.

*Chen, K., \& Chan, A. H. S. (2014). Predictors of gerontechnology acceptance by older Hong Kong Chinese. Technovation, 34, 126-135. https://doi.org/10.1016/j.technovation.2013.09.010

*Compeau, D., Higgins, C. A., \& Huff, S. (1999). Social cognitive theory and individual reactions to computing technology: A longitudinal study. Management Information Systems Quarterly, 23, 145-158. https://doi.org/10.2307/249749

*Davis, F. D. (1985). A technology acceptance model for empirically testing new end-user information systems: Theory and results (Doctoral dissertation). Sloan School of Management, Massachusetts Institute of Technology.

*Fishbein, M., \& Ajzen, I. (1975). Belief, attitude, intention and behaviour: An introduction to theory and research. Reading, MA: Addison-Wesley.

*Goodhue, D. L., \& Thompson, R. L. (1995). Task-technology fit and individual performance. Management Information Systems Quarterly, 19, 213-236. https://doi.org/10.2307/249689

Gräser, H. (2007). Entwicklungsberatung [Developmental counseling]. In J. Brandtstädter \& U. Lindenberger (Eds.), Entwicklungspsychologie der Lebensspanne. Ein Lehrbuch [Developmental psychology of life span. A textbook] (pp. 599-623). Stuttgart, Germany: Kohlhammer.

Gräser, H. (2012). Entwicklungsberatung [Developmental counseling]. In H.-W. Wahl, C. Tesch-Römer, \& J. P. Ziegelmann (Eds.), Angewandte Gerontologie. Interventionen für ein gutes Altern in 100 Schlüsselbegriffen [Applied gerontology. Interventions for good aging in 100 key terms] (pp. 169-174). Stuttgart, Germany: Kohlhammer.

Greve, W. (2001). Traps and gaps in action explanation: Theoretical problems of a psychology of human action. Psychological Review, 108, 435-451. https://doi.org/10.1037/0033-295X. 108.2.435

*Heerink, M., Kröse, B., Evers, V., \& Wielinga, B. (2010). Assessing acceptance of assistive social agent technology by older adults: The Almere model. International Journal of Social Robotics, 2, 361-375. https://doi.org/10.1007/s12369-010-0068-5

Lai, P. C. (2017). The literature review of technology adoption models and theories for the novelty technology. Journal of Information Systems and Technology Management, 14, 21-38. https://doi.org/10.4301/S1807-17752017000100002

Parette, P., VanBiervliet, A., \& Hourcade, J. J. (2000). Familycentered decision making in assistive technology. Journal of Special Education Technology, 15, 45-55. https://doi.org/ 10.1177/016264340001500104 
*Pikkarainen, T., Pikkarainen, K., Karjaluoto, H., \& Pahnila, S. (2004). Consumer acceptance of online banking: An extension of the technology acceptance model. Internet Research, 14, 224-235. https://doi.org/10.1108/10662240410542652

*Roelands, M., Van Oost, P., Depoorter, A. M., \& Buysse, A. (2002). A social-cognitive model to predict the use of assistive devices for mobility and self-care in elderly people. The Gerontologist, 42, 39-50. https://doi.org/10.1093/geront/42.1.39

* Rogers, E. M. (1983). Diffusion of innovations (3rd ed.). New York, NY: Free Press.

*Schulz, R. (2013). Facilitators and barriers to technology uptake: individual end-user perspectives. In R. Schulz (Ed.), Quality of life technology handbook (pp. 17-27). Boca Raton, FL: CRC-Press/ Taylor \& Francis Group.

*Suh, B., \& Han, I. (2002). Effect of trust on customer acceptance of Internet banking. Electronic Commerce Research and Applications, 1(2002), 247-263.

*Tarhini, A., El-Masri, M., Maged, A., \& Serrano, A. (2016). Extending the UTAUT model to understand the customers' acceptance and use of internet banking in Lebanon: A structural equation modeling approach. Information Technology \& People, 29, 830-849. https://doi.org/10.1108/ITP-02-2014-0034

*Taylor, S., \& Todd, P. A. (1995a). Understanding information technology usage: A test of competing models. Information Systems Research, 6, 144-176. https://doi.org/10.1287/isre.6. 2.144

*Taylor, S., \& Todd, P. A. (1995b). Assessing IT usage: The role of prior experience. Management Information Systems Quarterly, 19, 561-570. https://doi.org/10.2307/249633

*Thompson, R. L., Higgins, C. A., \& Howell, J. M. (1991). Personal computing: Toward a conceptual model of utilization. Management Information Systems Quarterly, 15, 125-143. https://doi. org/10.2307/249443

*Triandis, H. C. (1980). Values, attitudes, and interpersonal behaviour. In H. Howe \& M. Page (Eds.), Nebraska symposium on motivation (Vol. 27, pp. 195-259). Lincoln, NB: University of Nebraska Press.

*Venkatesh, V., \& Bala, H. (2008). Technology acceptance model 3 and a research agenda on interventions. Journal Compilation, 39, 273-312. https://doi.org/10.1111/j.1540-5915.2008.00192.x

*Venkatesh, V., \& Davis, F. D. (2000). A theoretical extension of the technology acceptance model: Four longitudinal field studies. Management Science, 46, 186-204. https://doi.org/10.1287/ mnsc.46.2.186.11926

*Venkatesh, V., Morris, M. G., Davis, G. B., \& Davis, F. D. (2003). User acceptance of information technology: Toward a unified view. Management Information Systems Quarterly, 27, 425-478. https://doi.org/10.2307/249688

*Venkatesh, V., Thong, J. Y. L., \& Xu, X. (2012). Consumer acceptance and use of information technology: Extending the unified theory of acceptance and use of technology. Management Information Systems Quarterly, 36, 157-178.

World Health Organization. (2001). International classification of functioning disability and health. Geneva, Switzerland: World Health Organization.

World Health Organization. (2015). World report on ageing and health. Geneva, Switzerland: World Health Organization.

*Zhou, T., Lu, Y., \& Wang, B. (2010). Integrating TTF and UTAUT to explain mobile banking user adoption. Computers in Human Behaviour, 26, 760-767. https://doi.org/10.1016/j.chb.2010.01.013

\section{History}

Received January 31, 2019

Revision received February 20, 2020

Accepted March 12, 2020

Published online July 6, 2020

\section{Acknowledgment}

We wish to thank two anonymous reviewers and the editors for very helpful comments on earlier drafts of this contribution.

\section{Conflict of Interest}

The authors declare that they have no conflict of interest.

\section{ORCID}

Diana Abri

(D) https://orcid.org/0000-0002-8226-2500

\section{Diana Abri}

Department of Behavioural and Cognitive Sciences Institute for Lifespan Development, Family, and Culture University of Luxembourg

11, Porte des Sciences 4366 Esch-sur-Alzette

Luxembourg

afsaneh.abrilahij@uni.lu

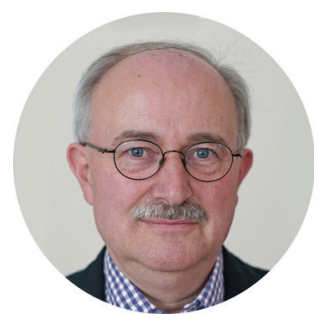

Thomas Boll is an assistant professor in life-span developmental psychology and geropsychology at the University of Luxembourg, Department of Behavioural and Cognitive Sciences, Institute for Lifespan Development, Family, and Culture. He focuses on the quality of adult child-parent relationships, emotional ambivalence in elder care, and the use of assistive technologies by older people. Cultural psychological perspectives increasingly supplement emotion and action theoretical approaches to these topics.

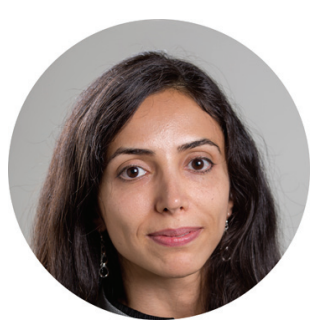

Diana Abri is a PhD student at the University of Luxembourg, Department of Behavioural and Cognitive Sciences, Institute for Lifespan Development, Family, and Culture. She is currently working on her $\mathrm{PhD}$ thesis exploring the use of assistive technologies in older people from action theoretical as well as cultural psychological perspectives. 